\title{
5 VIVÊNCIAS DOS ENFERMEIROS SOBRE MORTE E MORRER EM CUIDADOS INTENSIVOS: UMA REFLEXÃO FENOMENOLÓGICA
}

\author{
| Ricardo Silva ${ }^{1}$; Isabel Lage²; Ermelinda Macedo ${ }^{3} \mid$
}

\section{RESUMO}

CONTEXTO: Na atualidade a morte tem vindo a ser remetida para o hospital em detrimento do espaço íntimo do lar. As unidades de cuidados intensivos são altamente tecnológicas, abertas e destituídas de privacidade, onde a morte é um fenómeno frequente, algumas vezes inesperado, mas quase sempre traumático. Neste contexto, o enfermeiro é confrontado com diversos dilemas e emoções que podem comprometer a sua saúde mental e condicionar os cuidados que presta a alguém em final de vida.

OBJETIVOS: Explorar e descrever a experiência da morte e do morrer vivida pelos enfermeiros numa unidade de cuidados intensivos e de compreender o significado que lhe atribuem.

MÉTODOS: Optámos pela realização de um estudo qualitativo, exploratório e descritivo, de base fenomenológica. Os participantes (N=25) foram selecionados por conveniência tendo a amostra sido atingida por saturação teórica. Os dados foram recolhidos com recurso à entrevista não estruturada e analisados segundo a reflexão fenomenológica das narrativas, segundo a perspetiva de van Manen (2016).

RESULTADOS: Da análise das narrativas emergiram cinco temas: condicionantes da perceção dos enfermeiros sobre a morte e o morrer; práticas e contextos de cuidados ao doente em morte iminente; práticas e contextos de cuidados à família; mecanismos de adaptação; e conflitos internos na gestão dos cuidados.

CONCLUSÕES: Estes resultados permitem uma compreensão mais abrangente do objeto em estudo e orientam as intervenções dos enfermeiros para um cuidado centrado na pessoa, digno e confortador para a família e doentes que se confrontam com a morte neste e noutros contextos.

PALAVRAS-CHAVE: Morte; Enfermagem; Cuidados críticos

\section{RESUMEN}

\section{"Vivencias de los enfermeros sobre muerte y morir en cuidados críticos: Una reflexión fenomenológica"}

CONTEXTO: En la actualidad la muerte ha sido remitidas al hospital en detrimento del espacio íntimo del hogar. Las unidades de cuidados críticos son altamente tecnológicas, abiertas y carentes de privacidad, donde la muerte es un fenómeno frecuente, inesperado e traumático. En este contexto, el enfermero se enfrenta a diversos dilemas y emociones, que pueden comprometer su salud mental y, consecuentemente, condicionar los cuidados que presta a alguien en final de la vida.

OBJETIVOS: Explorar y describir la experiencia de la muerte y del morir vivida por los enfermeros en cuidados críticos, y comprender el significado que le atribuyen.

METODOLOGÍA: Optamos por la realización de un estudio cualitativo, exploratorio y descriptivo, de base fenomenológica. Los participantes $(\mathrm{N}=25)$ fueron seleccionados por conveniencia teniendo la muestra se ha alcanzada por saturación teórica. Los datos fueron recogidos con recurso a la entrevista no estructurada y analizados según la reflexión fenomenológica de las narrativas, según la perspectiva de van Manen (2016).

RESULTADOS: Del análisis de las narrativas surgieron cinco temas: condicionantes de la percepción de los enfermeros sobre la muerte y el morir; prácticas y contextos de atención al enfermo en muerte inminente; prácticas y contextos de cuidado de la familia; mecanismos de adaptación; y conflictos internos en la gestión del cuidado.

CONCLUSIONES: Estos resultados permiten una comprensión más amplia del objeto en estudio y pueden orientar las intervenciones de los enfermeros, para un cuidado más centrado en la persona, y más digno para la familia y enfermos, que enfrentan la muerte.

\section{DESCRIPTORES: Muerte; Enfermería; Cuidados críticos}

\section{ABSTRACT \\ "Nurses' experiences about death and dying in intensive care: A phenomenological reflection"}

BACKGROUND: Death is now being sent to the hospital at the expense of the intimate space of the home. Intensive care units are a highly technological space, open and deprived of privacy, where death is a frequent phenomenon, sometimes unexpected, but almost always traumatic. In this context, the nurse is confronted with diverse dilemmas and emotions that can compromise her mental health and consequently, condition the health care that gives to someone who experiences the end-of-life.

AIM: To explore and describe the experience of death and dying experienced by nurses in an intensive care unit, and understands the meaning attributed to it.

METHODS: We opted for a qualitative study, exploratory and descriptive, of phenomenological basis. The participants $(\mathrm{N}=25)$ were selected by convenience, and the sample being reached by theoretical saturation. The results were collected with the unstructured interview and analysed according to phenomenological reflection of the narratives in light of the prospect of van Manen (2016).

RESULTS: From the analysis of the narratives emerged five (5) themes: conditioners of nurses' perception of death and dying; practices and contexts of patient care in imminent death; practices and contexts of care to the family; mechanisms of adaptation; and internal conflicts in the management of care.

CONCLUSIONS: These results allow a broader understanding of the object under study and can guide the nurses' interventions towards more person-centered, more dignified and more comforting care for the family and patients facing death in this and other contexts.

\section{KEYWORDS: Death; Nursing; Critical care}

Submetido em 31-03-2018

Aceite em 30-06-2018

1 Mestre em Enfermagem da Pessoa em Situação Crítica; Enfermeiro especialista em Médico-Cirúrgica no Hospital de Braga, Braga, Portugal, ricardosilvarici@hotmail.com 2 Doutora em Enfermagem; Enfermeira Especialista em Médico-Cirúrgica; Professora Coordenadora na Universidade do Minho, Escola de Enfermagem, ilage@ese.uminho.pt 3 Doutora em Psicologia; Enfermeira Especialista em Enfermagem de Saúde Mental e Psiquiátrica; Professora Adjunto na Universidade do Minho, Escola de Enfermagem, Braga, Portugal, emacedo@ese.uminho.pt

Citação: Silva, R., Lage, I., \& Macedo, E. (2018). Vivências dos enfermeiros sobre morte e morrer em cuidados intensivos: Uma reflexão fenomenológica. Revista Portuguesa de Enfermagem de Saude Mental (20), 34-42. doi: 10.19131/rpesm.0224 


\section{INTRODUÇÃO}

Ao longo dos tempos a morte tem vindo a ser remetida para o hospital em detrimento do espaço íntimo do lar. As unidades de cuidados intensivos (UCI) diferenciamse pela tecnologia de ponta, meios avançados de monitorização e de terapêutica farmacológica, e têm como objetivo recuperar e tratar falências multiorgânicas que colocam a vida da pessoa em risco, atribuindo-lhe um significado curativo. Apesar do significado curativo destas unidades, a incidência de mortes ocorre com alguma frequência (Direção-Geral da Saúde, 2003; Urden, Stacy, \& Lough, 2008; Silva e Lage, 2010).

Desde sempre, os enfermeiros vivenciam uma realidade enraizada, norteada pela cura e pelo sucesso terapêutico. Contudo, muitas vezes são confrontados com a finitude humana, a qual põe em causa a tecnologia e o conhecimento científico. As situações de morte e do morrer em cuidados intensivos (CI) colocam aos enfermeiros desafios pessoais e profissionais que exigem uma alteração de paradigma de prestação de cuidados. Resultados de estudos sugerem que os enfermeiros neste contexto vivenciam a morte e o morrer envolvidos em sentimentos de respeito pela pessoa e sua família, disponibilidade e de defesa (advocacy) do doente (Kongsuwan \& Locsin, 2010; Valiee, Negarandeh, \& Nayeri, 2012; Robichaux \& Clark, 2006; Fridh, Forsberg \& Bergbom, 2009). Porém, é também evidente a carga emocional relacionada com a morte inesperada (King \& Thomas, 2013), que se traduz em sentimentos de ansiedade, depressão e falta de esperança, sendo que, a sua intensidade é diretamente proporcional à idade do doente, nível de consciência, morte cerebral ou doação de órgãos (Vallie et al., 2012). Questões relacionadas com a suspensão de medidas (Espinosa, Young, Symes, Haile, \& Walsh, 2010) e a não participação na tomada de decisão (Fridh et al., 2009; Espinosa et al., 2010) assumem, neste contexto de cuidados, sensações variáveis, que podem influenciar a experiência dos enfermeiros perante a morte e o morrer dos doentes que cuidam, adotando mecanismos de adaptação que visam preservar a sua saúde mental (Shorter \& Stayt, 2009).

A evidência assinala, também, a importância de uma gestão adequada da comunicação com a família durante o processo em que a morte será inevitável (King \& Thomas, 2013) considerando, ainda, que esta comunicação não deve cessar após a prestação dos cuidados post-mortem (King \& Thomas, 2013; Fridh et al., 2009).
Outros dados apontam para necessidade de formação adequada para prestar cuidados a pessoas em processo de morte, nomeadamente em ações paliativas (Espinosa et al., 2010).

Acresce, ainda, que, de acordo com Fridh et al. (2009), o processo de cuidar em fim de vida é desgastante para os enfermeiros em contexto de CI, sendo, por isso, necessário tempo para a recuperação, de forma a poderem cuidar de outros doentes que, aparentemente, tenham necessidade de cuidados semelhantes.

Considerando a evidência científica, a experiência profissional e a preocupação sobre a reflexão acerca da experiência da morte e do morrer dos doentes em UCIs, optou-se por se realizar um estudo qualitativo orientado pela questão de investigação: Que significado atribuem os enfermeiros à sua experiência de lidar com a morte e o morrer na unidade de cuidados intensivos? Foram definidos como objetivos: i) explorar o significado que os enfermeiros atribuem à morte e ao morrer numa unidade de cuidados intensivos; ii) descrever o significado que os enfermeiros atribuem à morte e ao morrer numa unidade de cuidados intensivos e; iii) compreender o significado que os enfermeiros atribuem à morte e ao morrer numa unidade de cuidados intensivos.

\section{MÉTODOS}

Optou-se por um estudo qualitativo e exploratório, de base fenomenológica, tendo por referência a perspetiva de van Manen (2016). Para van Manen (2016, p. 25) a "fenomenologia é, por um lado, a descrição da vivência da qualidade dos momentos vividos e, por outro lado, a descrição do significado das expressões de vida experienciadas". Foram estudados todos os enfermeiros de uma Unidade de Cuidados Intensivos Polivalente (UCIP), de um hospital da região norte de Portugal, que obedeciam aos seguintes critérios de elegibilidade: i) trabalharem na UCIP há pelo menos cinco anos; ii) terem vivido a experiência de morte no contexto da UCIP há pelo menos mais de uma semana, atendendo a que van Manen (2016) defende que a realidade da experiência vivida obtém-se quando surge a consciência refletida do fenómeno o que pressupõe um distanciamento temporal entre a experiência vivida e da experiência no momento. Embora o autor não dê indicação precisa do tempo necessário, a morte ocorre frequentemente na UCIP, razão pela qual se optou por este espaço temporal, ii) aceitarem de uma forma livre e esclarecida a participação no estudo e a gravação áudio da entrevista. 
Excluíram-se os participantes que estivessem a vivenciar um processo de luto pessoal, na medida em que as experiências recentes de morte de familiares e amigos poderiam influenciar as suas perspetivas e comprometer a profunda compreensão da consciência refletida, no que diz respeito à essência do significado do fenómeno da morte e do morrer do ponto de vista profissional. Recorreu-se a uma amostragem de conveniência, tendo a amostra teórica final sido atingida por saturação dos dados (Bogdan \& Biklen, 2013) após a realização de entrevistas a vinte e cinco participantes $(\mathrm{N}=25)$.

Considerando que a entrevista atende ao propósito específico de obter e explorar as narrativas constituindo, em si, um recurso à compreensão profunda da essência do significado do fenómeno em estudo (van Manen, 2016; Bogdan \& Biklen, 2013; Streubert \& Carpenter, 2013), recorreu-se à entrevista não estruturada. Do guião da entrevista constavam 2 partes. A primeira com quatro (4) questões de natureza biográfica e social (idade, sexo, habilitações literárias e tempo de exercício profissional) e uma (1) questão relativa à data da última experiência profissional de morte na UCIP. A segunda parte dizia respeito à questão aberta, a qual tinha como objetivo recolher informação o mais completa possível que permitisse compreender o significado que os enfermeiros atribuem à morte e ao morrer em $\mathrm{CI}$, sendo assim formulada: Sendo a morte e o morrer um acontecimento com o qual lida frequentemente na unidade de cuidados intensivos polivalente, que significado atribui a esta experiência?

O estudo foi aprovado pela Subcomissão de Ética para as Ciências da Vida e da Saúde (SECVS) da Universidade do Minho e pela Comissão de Ética para a Saúde do Hospital onde se realizou a investigação. Previamente procurou-se dar a conhecer ao entrevistado o propósito da entrevista bem como os objetivos do estudo, assegurando o anonimato e a confidencialidade dos dados recolhidos.

Foi assinado o consentimento informado, livre e esclarecido, sendo ainda assegurado que as gravações digitais seriam destruídas após a transcrição das narrativas e análise dos dados.

A colheita dos dados decorreu ao longo de três (3) meses na UCIP em ambiente propício para o efeito e de acordo com a disponibilidade dos participantes. As entrevistas tiveram duração média de onze (11) minutos, com um mínimo de cinco (5) e um máximo de vinte e dois (22) minutos.
Na impossibilidade de se realizar a validação das entrevistas pelos participantes após o final da entrevista, acordou-se o envio por correio eletrónico da transcrição da entrevista a cada participante tendo, assim, a possibilidade de eliminar e/ou retificar o seu conteúdo. Os dados foram sujeitos aos procedimentos da análise segundo o método da reflexão fenomenológica das narrativas (van Manen, 2016) com a intenção clara de descrever e interpretar as estruturas essenciais da experiência vivida. Para van Manen (2016, p. 92) "normalmente podemos ter 3 aproximações sobre aspetos temáticos encobertos ou isolados de um fenómeno em algum texto". Nesta perspetiva foram seguidos os procedimentos preconizados pelo autor de referência, tendo realizado: i) a aproximação holística; ii) a aproximação seletiva e iii) a aproximação detalhada ou linha por linha. Mais especificamente, através da aproximação holística pretendeu-se a aproximação ao texto como um todo, perguntando qual a frase que poderia captar o significado principal do mesmo, de modo a expressar esse significado através da formulação de uma frase. Em relação à aproximação seletiva, leu-se e releu-se diversas vezes o corpus de análise, questionando quais as frases ou declarações reveladoras do fenómeno em estudo. Já na aproximação detalhada, ou linha a linha, leu-se todas as frases ou frase a frase e perguntou-se o que é que a frase revelava sobre o fenómeno ou experiência descrita, de forma a emergirem os temas e subtemas (van Manen, 2016).

Da análise resultante das diferentes e sucessivas operações de redução dos dados emergiram cinco (5) temas principais (e respetivos subtemas): condicionantes da perceção dos enfermeiros sobre a morte e o morrer; práticas e contextos de cuidados ao doente em morte iminente; práticas e contextos de cuidados à família; mecanismos de adaptação; conflitos internos na gestão dos cuidados.

\section{RESULTADOS}

A média de idades dos participantes rondou os trinta e seis (36) anos. Sete (7) participantes são do sexo masculino e dezoito (18) participantes do sexo feminino, com idades compreendidas entre os vinte e sete (27) e os cinquenta e cinco (55) anos. A maioria dos enfermeiros eram detentores do grau de licenciado. Dos restantes, dois (2) possuíam pós-graduação, cinco (5) o título de especialista e, um (1) grau de mestre. Relativamente ao tempo do exercício profissional na UCIP, a média situou-se nos oito (8) anos. 
O tema Condicionantes da perceção dos enfermeiros sobre a morte e o morrer traduz um conjunto de elementos que geram diferentes entendimentos sobre este fenómeno. Das narrativas que deram origem a este tema pode inferir-se que a morte cerebral, a doação de órgãos, o "controlo" da morte, as crenças religiosas do enfermeiro, a proximidade com o doente e o estado emocional do enfermeiro são decisivos na perceção destes profissionais sobre a morte e o morrer.

"Em relação à morte cerebral, que é outra questão, que nos afeta, o grande problema muitas vezes é a ausência ou a falta de conhecimento da família e a dificuldade em aceitar e perceber no fundo a questão de morte cerebral, se associado à doação de órgãos" (E6).

"A morte nos CI é um fenómeno controlado na maior parte das vezes, portanto não há, salvo raras exceções, mortes surpresas (...) na UCI” (E2).

“(...) Existem situações que me custam mais, a morte de doentes do que outra, porque me relaciono com família, me relaciono com o doente, vejo a evolução do doente e às vezes custa-nos mais" (E10).

"Mas isto difere e, depois também acho que o nosso estado pessoal e psíquico também influencia um bocado. Às vezes estamos mais bem preparados, custa-nos menos, quando às vezes estamos mais em baixo, acho que é mais difícil encarar este processo de morte" (E10).

Ainda, no que diz respeito às condicionantes da perceção dos enfermeiros sobre a morte e o morrer, observa-se que algumas variáveis associadas ao próprio doente e família, designadamente a idade e a história de vida familiar, suscitam alguma reflexão e sentimentos.

"Às vezes ponho-me a pensar, ou na vida que a pessoa teve, ou nos filhos (...). Por trás daquela pessoa que está ali morta há uma história, há uma vida, há pessoas envolvidas, há família, amigos e, realmente tenho essa perspetiva... naquela altura de imaginar um bocadinho a vida" (E14).

"Quando são pessoas jovens sentimos sempre, mais do que fosse uma idade já avançada" (E24).

Relativamente ao tema Práticas e contextos de cuidados ao doente em morte iminente, e no que reporta ao trabalho em equipa, as opiniões dos enfermeiros oscilam entre a manifestação de que existe tomada de decisão unilateral (médica) e o trabalho em equipa. Emerge a futilidade terapêutica como uma prática presente, havendo, necessariamente, o recurso ao uso frequente dos fármacos e da tecnologia para manter a vida do doente. No entanto, as narrativas também evidenciam a prática do cuidado digno que é prestado à família e ao doente em morte iminente, bem como, o devido reconhecimento do papel do enfermeiro.
"Eu acho que apesar de nós sermos importantes na equipa, não temos qualquer poder de decisão em suspender ou não medidas a um doente, apesar de se falar que esta decisão é uma decisão multidisciplinar, não é, quem decide é o médico" (E17).

"Aqui eutanásia não. Mas distanásia tem-se a noção que se faz, investem, investem, investem..." (E3).

"E depois temos os casos em que eles investem...investem e sabem que não vão ter resultados. Eles sabem que não vão recuperar, só que muitas vezes eles não querem tomar a decisão) (E24).

"Aqui, há uma preocupação pelo conforto do doente. Mesmo em situações de parar de escalar medidas, há sempre tanto da nossa parte como dos médicos, analgesia e conforto" (E8).

"E depois, são pessoas que além de enfrentar aquele processo de dor e de perda, também têm uma palavra de apreço para connosco e, isso acaba por ser sempre gratificante, porque ainda nos agradecem" (E11).

No que se refere aos contextos de cuidados, os participantes refletem sobre as diferenças relacionadas com os cuidados associados à morte e ao morrer nas UCI e em outras unidades onde já tinham prestado cuidados a doentes em fim de vida.

"Eu comecei a trabalhar no Instituo Português de Oncologia, e lá temos uma perceção da morte... um bocadinho diferente. Aqui é mais tecnológico e, às vezes temos a tendência de ver a família como uma máquina” (E3).

"Aqui a morte é mais humanizada... no serviço de urgência às vezes os doentes faleciam e nós nem dávamos conta, não dávamos por isso (...) Aqui não, salvo exceções muito raras em que o doente agudiza muito rapidamente e acaba por falecer. Habitualmente é sempre uma morte mais acompanhada" (E4).

Quanto ao tema Práticas e contextos de cuidados à família existe um conjunto de variáveis que influencia as perceções dos enfermeiros sobre o fenómeno em estudo, fundamentalmente associadas ao conforto e privacidade, tendo em conta a importância de promover a presença da família na morte e no morrer, e o respeito pela vontade do doente e família.

As narrativas sugerem também a necessidade de o enfermeiro prestar apoio psicológico, ser advogado e defensor da família.

Nesse sentido, o propósito da implementação da consulta de follow-up, às famílias que veem partir o seu familiar e a necessidade de um apoio no âmbito da psicologia, ilustram alguns significados. 
“Têm livre acesso à unidade, portanto, não há restrições no número de visitas como é habitual. Disponibilizamos a entrada dos familiares, seja a que hora for" (E4). "Estes cuidados em fim de vida podem estar expressos à família, e muitas vezes nós não temos esse conhecimento, porque também não o procuramos. Agora com a nova lei do testamento vital, provavelmente poderá cada vez mais existir esse conhecimento (...)" (E6).

"Claro que temos de ser humanos, criar empatia com as famílias, ter respeito por esses momentos, e facilitar tudo o que seja possível no apoio à família" (E21).

"Um dia não são dias e vai-se fazendo à medida que se pode, alguns dias melhor, outros dias pior, mas acho que devia haver um follow-up, mesmo das famílias que perdem alguns familiares aqui” (E12).

"E ter o apoio do psicólogo, acho que é muito importante. Mesmo durante a visita, acho que devíamos ter aqui uma pessoa alguns dias por semana, fixa para o apoio aos familiares" (E14).

Ainda no âmbito deste tema, surgem alguns elementos associados à gestão de más notícias e ao processo de luto das famílias como condicionantes da experiência dos enfermeiros.

"Mas existem situações que nos custam sempre mais... são aquelas situações em que a família não está preparada para receber a notícia de que o seu familiar vai morrer" (E3).

"Não foi um doente que faleceu passado umas horas, como era perspetivado, e à família custou-lhe imenso [...]. O doente estava sedado e com analgesia, esse aspeto nós tínhamos salvaguardado, o doente estava confortável. Mas, o mesmo não se passava com a família e acho que aí é mais complicado o processo de luto, porque acaba por ser um luto, um luto que apesar de a pessoa estar viva é complicado" (E7).

O tema Mecanismos de adaptação sustenta a importância da adaptação psicológica, relacionada com as experiências de morte e do morrer vividas pelos enfermeiros na UCI. Os relatos traduzem a necessidade de os enfermeiros adotarem mecanismos de adaptação, designadamente, a fuga, o apoio entre os pares e familiares e o recurso às emoções.

"Não podemos apegar-nos muito aos doentes, não podemos ligar-nos emocionalmente, porque também dificulta a realização do nosso trabalho (...). Se não nos defendermos e nos distanciarmos um bocadinho, depois não conseguimos lidar com a próxima situação" (E21).
"Quando eu saio daqui vou a conduzir com o rádio ligado até casa e, em alguns dias, chego a casa e tenho efetivamente de falar daquilo que se passou, porque acaba por ser maior..." (E3).

"E já chorei em frente à família, a chorar efetivamente, custou-me imenso, mas não consegui, não conseguia, é muito complicado, muito, muito complicado" (E3).

Finalmente, o tema Conflitos internos na gestão de cuidados, parece dar conta da existência de duas realidades, que não sendo opostas surgem, aparentemente, como incompatíveis, perante a evidência das circunstâncias. Este facto gera em alguns enfermeiros um sentimento de conflito interno, na medida em que são arredados das decisões que deveriam ser tomadas no seio da equipa multidisciplinar. Falamos da discordância nos critérios de admissão na UCI e na discordância na transferência do doente face à sua situação clínica.

"E depois há casos de doentes que entram na unidade que no meu ver não têm critérios para entrar; alguns acabam por morrer logo na entrada no serviço, ainda na semana passada aconteceu um caso" (E24)

"Outro aspeto, que também vou falar e este é mais recente... é transferir o doente para outro hospital sem viabilidade, ou seja, o doente vai em peça em $\mathrm{T}$, mas vai com indicação para não investir, porque não tem viabilidade. Para mim é assustador (...)” (E6).

"Aqui também acontece uma coisa que para mim é bastante penosa, normalmente os doentes não morrem aqui, ou seja, a partir do momento em que se decide suspender medidas, o doente é colocado, ou em peça em T, ou outra e, é transferido para outro serviço. A mim custa-me um bocado ..."(E12).

\section{DISCUSSÃO}

A perspetiva dos enfermeiros sobre a morte e o morrer é condicionada por elementos de natureza vária podendo trazer-lhes sofrimento, quando envolvidos com a morte do doente, particularmente quando se trata de doentes jovens, de mortes inesperadas e, de histórias de vida carregadas por um grande simbolismo afetivo e emocional, tal como descrevem King \& Thomas (2013) e Espinosa et al. (2010). O sofrimento emocional relacionado com a morte cerebral e a doação de órgãos encontra paralelo nos estudos de Ronayne (2009) e de Shorter \& Stayt (2009), onde também realçam a grande prevalência de jovens com diagnóstico de morte cerebral e a doação de órgãos, algo que em muitas ocasiões se torna sofrível para os enfermeiros, nomeadamente 
quando criam uma recriação do "eu" pela proximidade de idades, ou mesmo, quando se identificam com o acontecimento, porque encaram aquela realidade como se fosse a dos "seus". A ideia de morte "controlada" nas UCI, manifestada por alguns participantes deste estudo, dá eco ao sustentado por Shorter \& Stayt (2009), quando afirmam, que os doentes estão monitorizados e com suporte de medidas, que visam o controlo de todo o processo.

A proximidade quase afetiva que, por vezes, o enfermeiro estabelece com o doente e família é, frequentemente, sinónimo de um maior grau de sofrimento, nos momentos que antecede e no momento em que acontece a morte.

Nesse sentido, a experiência de luto é tanto ou mais perturbadora quanto maior for o vínculo ao doente e à família. As relações de proximidade, bem como a experiência de luto, também se veem refletidas nos estudos de Thompson, Austin, \& McGrath (2010) e de Shorter \& Stayt (2009). Por outro lado, o estado emocional dos enfermeiros condiciona a sua perceção sobre a morte e o morrer, tal como defende Espinosa et al. (2010). Os mesmos referem que deve ser assegurada a condição psicológica afetiva e emocional do enfermeiro, no momento em que se atribui um doente em morte iminente, protegendo, desse modo, o profissional enquanto pessoa, mas também o doente e a família. Como forma de assegurar o mentalmente "são", alguns participantes abordaram a questão da crença, como forma de um melhor entendimento sobre a morte e o morrer, tendo por base a sua própria crença e o suporte que encontram na sua religião, apoiando os resultados de Valiee et al. (2012) e de Souza, Ribeiro, Rosa, Gonçalves, Silva, e Barbosa (2013).

A pertinência da formação foi abordada apenas por um participante do estudo, embora seja um assunto de análise por alguns investigadores que destacam a importância da reflexão e da discussão sobre a morte e o morrer nas salas de aula (Thompson et al., 2010).

No tema Práticas e contextos de cuidados ao doente em morte iminente, as narrativas deixam claro que a aplicação de medidas fúteis é, por vezes, uma realidade quando se assiste ao investimento desmesurado assente na farmacologia e na tecnologia avançada, em detrimento de ações que tenham somente em conta a humanização da morte.

Por outro lado, o uso de fármacos e de meios tecnológicos permite o "controlo da situação" e o amenizar de um qualquer sentimento de culpa.
As implicações relacionadas com a futilidade terapêutica e com o uso insipiente de critérios e princípios éticos são também aspetos apontados por alguns estudos (Robichaux \& Clark, 2006; Fridh et al., 2009; Espinosa et al., 2010, Shorter \& Stayt, 2010). As narrativas permitem inferir, ainda, que os enfermeiros procuram minorar o desconforto, o sofrimento e a dor, com a intenção clara de promoverem a dignidade humana na morte do doente, princípio também corroborado por Shorter \& Stayt (2010).

Algumas práticas e condutas descritas nas narrativas parecem deixar transparecer uma filosofia curativa, em detrimento duma perspetiva paliativa. Todavia, os participantes do estudo revelaram comportamentos que traduzem respeito absoluto pela dignidade da pessoa que está a morrer, proporcionando o conforto e o controlo da dor, dados que são corroborados por King \& Thomas (2013). As palavras de reconhecimento por parte das famílias e, por vezes, do doente em fim de vida são descritas com orgulho e sentido de dever cumprido. É notório que os vários contextos de cuidados influenciam determinantemente o entendimento e a forma como experienciam a morte dos seus doentes na UCI, na medida em que, as UCI permitem arredar a consciência da morte e do doente, pelo uso devido de fármacos e da tecnologia, algo inacessível às enfermarias onde, por vezes, a morte ocorre de uma forma descontrolada e descuidada, tal como referem Shorter \& Stayt (2009).

A partir das narrativas pode constatar-se a existência do trabalho em equipa, no entanto, a decisão de suspender medidas é uma decisão unilateral e exclusivamente médica. Também, dados vinculados aos estudos de Fridh et al. (2009) e de Amaral, Soares, e Souza (2010) traduzem dificuldades no relacionamento e na colaboração entre equipas.

Quanto à falta de intervenção dos enfermeiros na tomada de decisão, os estudos de Robichaux \& Clark (2006), de Fridh et al. (2009) e de Espinosa et al. (2010), vêm apoiar estes resultados, no sentido da tomada de decisão ser unilateral, não havendo qualquer tipo de decisão conjunta que tenha em conta a perspetiva médica e de enfermagem.

Relativamente ao tema Práticas e contextos de cuidados à família, a privacidade no momento da morte no contexto da UCI é relatada com alguma preocupação, por nem sempre ser possível proporcionar as melhores condições nesta unidade de cuidados, num momento imbuído de enorme simbolismo e desgaste emocional. 
No entanto, são evidentes algumas ações que visam contornar as vicissitudes da UCI, com o objetivo de proporcionar a melhor privacidade e conforto à família. Kongsuwan \& Locsin (2010) revelam que os participantes do seu estudo relatam dificuldade em conseguir o ideal de privacidade e de conforto no momento da morte, devido ao ruído, à logística e espaço físico, informação também sustentada por Fridh et al. (2009).

Os dados relacionados com a possibilidade da presença da família no momento da morte do seu familiar vão de encontro aos resultados do estudo de Fridh et al. (2009). Depreende-se, ainda, que os participantes, ao incentivarem a presença da família, também pretendem promover a relação psicológica e física entre o doente em fase final de vida e os familiares. Os participantes do estudo revelam também que o apoio psicológico prestado pelo enfermeiro tem como único destinatário a família. Esse apoio traduz grande sobrecarga emocional, para além da relacionada com os cuidados que estão associados à morte e ao morrer. Alguns estudos abordam o apoio psicológico, tendo em conta as necessidades do enfermeiro e não propriamente da família (Shorter \& Stayt, 2009; Thompson et al., 2010). No entanto, estudos que abordam a morte cerebral e a doação de órgãos enfatizam a atenção que os enfermeiros dispensam à família do ponto de vista psicológico no esclarecimento do conceito de morte cerebral e na gestão da doação de órgãos (Pearson, Robertson, Walsh, \& Fitzgerald, 2001; Ronayne, 2009).

Em todas as circunstâncias, mas particularmente em situações de confronto com a morte, a gestão de más notícias exige competências de comunicação, fundamentalmente quando a família não está à espera nem preparada para as receber, ou a finitude não é previsível. Algumas das narrativas traduzem as dificuldades sentidas pelos enfermeiros, quando estes são os interlocutores e gestores das más notícias. King \& Thomas (2013) apontam para que o domínio da comunicação da morte e do morrer resulte num valor acrescentado e numa poderosa arma terapêutica. Por sua vez, Espinosa et al. (2010) vão de encontro às dificuldades narradas pelos participantes, sugerindo ações de formação e protocolos dirigidos à gestão das más notícias.

Os dados relativos à gestão do processo de luto das famílias ancoram-se nos resultados do estudo de Forsberg, Flodén, Lennerling, Karlsson, Nilsson, \& Fridh (2014), onde é manifesto o respeito e cordialidade pelo doente e pela família em todo o processo de luto, através de uma adequada gestão do tempo, da comunicação, do silêncio e do espaço vital.
Por outro lado, o enfoque dessa abordagem é mais abrangente e profundo nos fenómenos da morte cerebral e doação de órgãos (Pearson et al., 2001; Ronayne, 2009).

O follow-up, percebido como o regresso da família à UCI no pós-morte do seu familiar, foi lembrado nas narrativas como intenção futura. Fridh et al. (2009) e Forsberg et al. (2014), ao abordarem o follow-up, ressalvam a importância do regresso à UCI, porque, assim, assegura-se o esclarecimento das dúvidas suscitadas pela família, a possibilidade de ouvir as suas opiniões, quanto aos cuidados prestados e, por fim, o apoio no processo de luto.

As narrativas agregadas ao tema Mecanismos de adaptação são consistentes com a adoção de comportamentos de fuga por parte dos enfermeiros, como forma de se defenderem do processo de morte do doente e do sofrimento vivido pela família. Estas formas de estar perante a morte também são apoiadas por Shorter \& Stayt (2009) e por Espinosa et al. (2010).

Nestes estudos depreende-se que a autoproteção emocional leva o enfermeiro a evitar uma relação de proximidade com o doente e com a família, como forma de evitar sofrimento nos momentos da morte e do morrer. Espinosa et al. (2010) definem-nos como "o enfermeiro duro" (p. 279).

As narrativas também abordam a necessidade de os enfermeiros chorarem na presença da família e do doente no momento da morte, bem como, na procura dos colegas ou da família nos momentos de maior sobrecarga emocional. O choro, entendido como um mecanismo de adaptação, também foi referido no estudo de Thompson et al. (2010) e de Espinosa et al. (2010). Thompson et al. (2010), Shorter \& Stayt (2009) e Espinosa et al. (2010) realçam a procura ou o apoio dos colegas de trabalho como uma mais-valia, permitindo aos enfermeiros a autoproteção emocional, bem como, a reflexão sobre as experiências vivenciadas da morte e do morrer na UCI.

O tema Conflitos internos na gestão dos cuidados revela o desacordo na admissão de doentes com pouca probabilidade de recuperação e de sobrevivência funcional, o que vai de encontro ao pensamento de Rios (2001). As narrativas, revelam, também, divergências quanto às transferências de doentes para outras UCIP ou serviços, quando os mesmos estão em morte iminente. King \& Thomas (2013) acrescentam que algumas dessas transferências ocorrem pela necessidade de vagas, tendo acontecido nos serviços do mesmo hospital. 


\section{CONCLUSÃO}

As narrativas que dão voz aos participantes permitiram uma melhor compreensão do significado que os enfermeiros da UCIP atribuíram à morte e ao morrer.

Os dados deste estudo indicam que os enfermeiros, perante a morte e o morrer de um doente, vivem experiências diversas que condicionam diferentes perceções sobre este fenómeno.

A perceção da morte e do morrer é condicionada por diversos fatores.

É evidente a dificuldade de alguns participantes em aceitarem a morte dos doentes mais jovens, bem como histórias de vida com eventos dramáticos, embora assumam a morte como um fenómeno natural, mas por vezes banalizado. As práticas e contextos de cuidados ao doente e família são determinantes na perspetiva dos enfermeiros, observando-se o sofrimento das famílias que exige dos enfermeiros competências de comunicação adequadas, relativamente à gestão do luto e à comunicação de más notícias.

Acresce ainda, que os enfermeiros se preocupam com a defesa dos direitos dos doentes e da família, na promoção da presença da família no momento da morte, tendo em atenção o direito à privacidade. A morte e o morrer geram uma grande carga emocional nos enfermeiros, levando-os a adotar mecanismos de adaptação permitindo autoproteção emocional, bem como, a reflexão sobre as experiências vivenciadas da morte e do morrer na UCI.

Emergem ainda alguns conflitos internos na gestão dos cuidados, designadamente, quando se trata de decisões unilaterais que envolvem o potencial de recuperação e as transferências de doentes em morte iminente para outras unidades de cuidados.

Os dados deste estudo apontam para que diferentes variáveis influenciem a perceção da morte e do morrer dos enfermeiros.

Os participantes identificam alguns aspetos que podem contribuir para melhoria dos cuidados, nomeadamente aspetos relacionados com o equilíbrio psicológico dos profissionais, a necessidade de um atendimento à família personalizado e humanizado, a importância de promover um eficaz trabalho de equipa, a necessidade de formação acrescida sobre a morte e o morrer, de comunicação de más notícias e de gestão do luto.

\section{IMPLICAÇÕES PARA A PRÁTICA CLÍNICA}

Este estudo pode dar um contributo significativo para que a morte seja um acontecimento cada vez mais humanizado e mais digno, tanto para quem o vive, como para os profissionais que assistem os doentes e famílias permitindo, também, uma análise das práticas de cuidados em UCI, unidades onde a morte ocorre com muita frequência. A análise dos seus resultados sugere que a formação em fim de vida, que inclua o sofrimento, a comunicação de más notícias e a gestão do luto e estratégias de coping dirigida a enfermeiros que trabalham em UCI, possa constituir um caminho para a melhoria contínua dos cuidados e a melhor preparação dos enfermeiros para o enfrentamento destes processos. Ainda, as consultas de follow-up podem funcionar como um recurso para a recolha de informação relevante sobre os cuidados na morte e no morrer, com o objetivo de melhorar o acompanhamento das famílias e do doente ao longo de todos os momentos associados à morte e ao morrer, incluindo o processo de luto.

\section{REFERÊNCIAS BIBLIOGRÁFICAS}

Amaral, M., Soares, E., \& Souza, R. (2010). Relacionamento interdisciplinar de profissionais de saúde que atuam em unidades de alta complexidade. Revista de Pesquisa: cuidado é fundamental online, 2 (1), 646-654. Disponível em: http://www.seer.unirio.br/index.php/ cuidadofundamental/article/download/585/pdf_11

Bogdan, R., \& Biklen, S. (2013). Investigação qualitativa em educação: uma introdução à teoria e aos métodos. (12a ed.). Porto: Porto Editora.

Direção-Geral da Saúde. (2003). Cuidados intensivos: recomendações para o seu desenvolvimento. Disponível em: http://www.dgs.pt/upload/membro.id/ficheiros/ i006185.pdf

Espinosa, L., Young, A., Symes L., Haile, B., \& Walsh, T. (2010). ICU nurses experiences in providing terminal care. Critical Care Nursing Quarterly, 33 (3), 273-281. Doi: 10.1097/CNQ.0b013e3181d91424

Forsberg, A., Flodén, A., Lennerling, A., Karlsson, V., Nilsson, M., \& Fridh, I. (2014). The core of after death care in relation to organ donation - a grounded theory study. Intensive and Critical Care Nursing, 30, 275-282. Doi: 10.1016/j.iccn.2014.06.002. 
Fridh, I., Forsberg, A., \& Bergbom, I. (2009). Doing one's utmost: nurses' descriptions of caring for dying patients in an intensive care environment. Intensive and Critical Care Nursing, 25, 233-241. Disponível em: https://ac.els-cdn.com/S0964339709000640/1-s2.0S0964339709000640-main.pdf?_tid=d6a87bab-5f484cb9-89d3-35756dbc20e5\&acdnat=1534350348_1c81f 0e44afa85fe152837472658bf9d

King, P. \& Thomas, S. (2013). Phenomenological study of ICU nurses experiences caring for dying patients. Western Journal of Nursing Research, 35 (10), 12921308. Doi: $10.1177 / 0193945913492571$

Kongsuwan, W., \& Locsin R. (2010). Aesthetic expressions illuminating the lived experience of thai icu nurses caring for persons who had a peaceful death. Holistic Nursing Practice, 24 (3), 134-141. Doi: 10.1097/ HNP.0b013e3181dd4000

Pearson, A., Robertson, S., Walsh, K., \& Fitzgerald, M. (2001). Intensive care nurses experiences of caring for brain dead organ donor patients. Journal of Clinical Nursing, 10, 132-139. Disponível em: https:// onlinelibrary.wiley.com/doi/epdf/10.1046/j.13652702.2001.00447.x

Rios, M. (2001). Ética em cuidados intensivos. In Serviço de Cuidados Intensivos - Hospital de S. João (Ed.), Manual do Interno de Cuidados Intensivos (pp. 481487). Porto: Medisa.

Robichaux, C., \& Clark, A. (2006). Practice of expert critical care nurses in situations of prognostic conflict at the end of life. American Journal of Critical Care, 15 (5), 480-491. Disponível em: http://ajcc.aacnjournals. org/content/15/5/480.full.pdf+html

Ronayne, C. (2009). A phenomenological study to understand the experiences of nurses with regard to brainstem death. Intensive and Critical Care Nursing, 25, 9098. Doi: 10.1016/j.iccn.2008.06.001
Shorter, M., \& Stayt, L. (2009). Critical care nurses experiences of grief in an adult intensive care unit. Journal of Advanced Nursing, 66 (1), 159-167. Disponível em: https://onlinelibrary.wiley.com/doi/epdf/10.1111/ j.1365-2648.2009.05191.x

Silva, A. \& Lage, M. (2010). Enfermagem em cuidados intensivos. Coimbra: Formasau.

Souza, L., Ribeiro, J., Rosa, R., Gonçalves, R., Silva, C., e Barbosa, D. (2013). A morte e o processo de morrer: sentimentos manifestados por enfermeiros. Revista electrónica trimestral de Enfermeria, 12 (32), 230-237. Disponível em: http://scielo.isciii.es/pdf/eg/v12n32/ pt_administracion4.pdf

Streubert, H. \& Carpenter, D. (2013). Investigação qualitativa em enfermagem: Avançando o imperativo humanista. ( $5^{\mathrm{a}}$ ed.). Loures: Lusodidacta.

Thompson, G., Austin, W., \& McGrath, J. (2010). Novice nurses first death in critical care. Dynamics, 21 (4), 26-36. Disponível em: https://content.ebscohost.com/ ContentServer.asp? $\mathrm{T}=\mathrm{P} \& \mathrm{P}=\mathrm{AN} \& \mathrm{~K}=104953319 \& \mathrm{~S}=\mathrm{R}$ $\& \mathrm{D}=\mathrm{rzh} \&$ EbscoContent $=\mathrm{dGJyMNXb} 4 \mathrm{kSep} 7 \mathrm{M} 4 \mathrm{v} \% 2 \mathrm{~B}$ vlOLCmr1Cep7BSsai4TK\%2BWxWXS\&ContentCust omer=dGJyMOzprkiuqLdIuePfgeyx43zx

Urden, L., Stacy, K., \& Lough, M. (2008). Thelan's enfermagem de cuidados intensivos. Diagnóstico e intervenção ( $5^{\mathrm{a}}$ ed.). Loures: Lusodidacta.

Valiee, S., Negarandeh, R., \& Nayeri, N. (2012). Exploration Iranian intensive care nurses experience of end-oflife care: a qualitative study. Nursing in Critical Care, 17 (6), p. 309-315. Doi: 10.1111/j.1478-5153.2012.00523.x

Van Manen, M. (2016). Researching lived experience, Second Edition: Human science for an action sensitive pedagogy. (2a ed.). New York: Suny Press. 